\title{
SARGON CỦA XỨ AKKAD - NGƯÒII LẬP NÊN ĐẾ CHẾ ĐẦU TIÊN TRONG LỊCH SỬ NHÂN LOẠI
}

(\#hoangtocphuongdong) Lưỡng Hà là một vùng bình nguyên nằm giữa hai con sông Tigris và Euphrates thuộc Tây Á. Người Hy Lạp cổ đại gọi vùng đất này là Mosopotamie (nghĩa là vùng đất nằm giữa hai con sông lớn). Vùng Tây Á chủ yếu là vùng đất có nhiều sa mạc và những dãy núi lớn, vì vậy, vùng đất màu mỡ nằm gần những con sông là nơi diễn ra những tranh chấp giữa các tộc người.

Một trong những nền văn minh đầu tiên của khu vực Lưỡng Hà chính là nền văn minh của người Sumer (khoảng từ thiên niên kỷ IV TCN). Đầu thiên niên kỷ III TCN, người Akkad thuộc tộc Semit từ thảo nguyên Syri xâm nhập và lập nên đế chế Akkad.

Cái tên 'Sargon' được cho là bản dịch của người Akkadian là 'Sarukinu', dịch qua Tiêng anh là 'The True King', ông được nhắc đến là Sargon của xứ Akkad, Sargon Đại đế hay Sargon I (để phân biệt với Hoàng đế Sargon của Assyria sau này).Với tài năng của mình, nhà lãnh đạo nổi tiếng của xứ Akkad đã làm chủ được một vùng lãnh thổ rộng lớn trải dài hầu hết khu vực Lưỡng Hà, chinh phục đển những khu vực xa xôi nhất, và sử dụng khả năng lãnh đạo để phát triển để chế phát triển cường thịnh. Ngoài ra, Sargon còn là chủ đề của những câu chuyện huyền thoại về sự vươn lên đạt tới quyền lực đáng ngưỡng mộ từ nguồn gốc khiêm tốn cho tới sự chinh phục cả khu vực Lưỡng Hà được đề cập trong văn học Assyria và Babylon sau này.

Phần lớn người ta biết tới ông nhờ những câu chuyện có chọn lọc, nổi tiếng nhất là về thời điểm ông được sinh ra, câu chuyện rất giống với câu chuyện về Moses trong Kinh Thánh, chỉ khác ở chỗ cậu bé Moses được thả xuống dòng sông Nile còn Sargon được thả xuống dòng sông Euphrates.

Truyền thuyết kể rằng, mẹ của Sargon là 1 nữ tư tế Akkad có nhiệm vụ trông coi đền thờ (có nghi vấn mẹ ông là một cô gái điếm thiêng liêng của nữ thần Ishtar) đã mang thai một đứa con ngoài ý muốn nên đã bỏ đứa bé trong một chiếc giỏ thả trôi trên dòng sông Euphrates. Một người đàn ông tên là Akki cứu sống, mang về nhà nuôi và đặt tên là Sargon. Akki là một người thợ làm vườn cho Ur Zababa, người đứng đầu thành Kish, Sargon lớn lên trở thành hầu rượu thân cận cho Ur - Zababa. Không rõ lý do gì mà Ur - Zababa cảm thấy sự nguy hiểm đến từ Sargon, ông ta lệnh cho Sargon đem 1 lá thư bằng đất sét với thông điệp hòa bình gửi cho Loly-zage-si (vua của Umma), nhưng thực ra nội dung bức thư là nhờ giêt Sargon. Tuy nhiên, Loly-zage-si lại đề nghị Sargon hợp tác để chinh phục Kish. Sau khi Ur-Zababa bị phế truất, Sargon và Loly-zage-si trở mặt và 
Sargon đã chiến thắng trong trận chiến thành Kish. Để tăng thêm sự xúc phạm tới vị vua của Umma, Sargon đã cho quấn một sợi dây quanh cổ vị vua này và đưa ông ta tới Nippur. Sargon đã cho Lylozage-si diễu hành qua cổng của Extil để vị thần bảo trợ của ông ta là Extil (thần Extil là một trong những vị thần được nhiều người tôn thờ nhất trong số những người con của Anu và Ki trong thần thoại Lưỡng Hà, vị thần bảo trợ của Sargon là nữ thần chiến tranh Ishtar) thấy được sự yếu đuối của ông ta.

Khoảng 5.00o năm TCN, Sumer là vùng đất sở hữu những thành phố đầu tiên và phồn thịnh của loài người, ở đây ngoài việc đào kênh, trồng cây và nuôi gia súc, người dân Sumer còn đặc biệt coi trọng việc buôn bán. Những cư dân Sumer sẽ đổi lương thực thực phẩm thừa để lấy kim loại, dụng cụ lao động, thuyền từ những lái buôn đến từ Pakistan hay Afghanistan, nhờ đó mà người Sumer trở nên giàu có, những thành phố cũng ngày càng phát triển. Các thành phổ lớn này lại bị Sargon Đại đế của xứ Akkad thâu tóm, tạo thành một đế quốc trải rộng từ Syria đến Vịnh Ba Tư trong khoảng thời gian từ 2330 đến $2275 \mathrm{TCN}$ (Một số tư liệu ghi chép rằng để mở rộng tới Vịnh Ba Tư, Sargon đã giành được tới 34 chiến thắng). Sau khi đã chinh phục được nhiều vùng đất gồm hầu hết khu vực Lưỡng Hà và các phân lãnh thổ rộng lớn ở phía Đông Địa Trung Hải, Sargon thành lập Đế chế Akkad (hay còn gọi là Thành phố Agade) vào năm 2334 TCN. Sargon cũng không ngừng mở rộng đế chế, tiếp tục đánh bại Elamites về phía Đông (miền Tây Iran), ở phương Tây, thì chinh phục Syria và Anatolia.

Nổi tiếng với nhiều cuộc chinh phục, nhưng việc chinh chiến không là duy nhất trong suy nghĩ của vị vua này, ông còn nghĩ nhiều biện pháp để cai trị toàn bộ lãnh thổ ông chiếm được một cách có hiệu quả. Vì vậy, cứ mỗi thành bang Sargon chinh phục được đều nhanh chóng thiết lập một bộ máy cai trị, đứng đầu là một người Akkad có năng lực và trung thành.

Sargon quyết tâm chinh phục các vùng đất với mục tiêu là kiểm soát con đường thương mại, ngăn chặn việc thủ lĩnh ở các địa phương thu phí các đoàn buôn của Akkad. Điều này được thể hiện qua những việc làm của ông.

Sargon lần lượt kiểm soát khu rừng tuyết của Lebanon và mỏ bạc của Anatolia, đây là 2 nơi cung cấp nguồn nguyên liệu thô rất quý giá, chúng được dùng để buôn bán ở Oman và dọc theo vùng vịnh. Để bảo vệ các quyền lợi về thương mại, Sargon cũng cho tổ chức một đội quân đông đảo khoảng 5.400 người.

Sargon kiểm soát toàn bộ tuyến đường thương mại đi ngang qua Vương quốc, đánh thuế những thương nhân muốn đi qua Vương quốc để lấy tiền trả cho binh lính, nghệ sĩ và những người phụ trách ghi chép của hoàng gia để cái tên 'Sargon' luôn được vinh danh trong những tác phẩm điêu khắc và chữ khắc. 
Sargon cũng đưa ngôn ngữ của Akkad trở thành ngôn ngữ chính thức trên khắp khu vực Lưỡng Hà. Sau khi loại bỏ rào cản về ngôn ngữ, Sargon cho thúc đẩy trao đổi, mua bán không chỉ trong khu vực Lưỡng Hà mà còn ở các vùng đất xa xôi. Được biết, người Ấn Độ đã từng đến đây và mang theo ngọc trai, ngà voi và nhiều thứ quý hiếm khác để đổi lấy các sản phẩm làm từ len và dầu oliu. Thời kỳ này chưa xuất hiện tiền đúc, vì vậy mà các thương nhân sau khi xác định giá trị của món hàng đã dùng các kim loại quý như vàng, bạc, đồng để trả thay cho tiền.

Sargon cũng cho tiến hành xây sửa những con đường mới, tiến hành nhiểu cải cách để phát triển thủy lợi, nghệ thuật và khoa học kỹ thuật. Dưới thời kỳ trị vì của Sargon Đại đế, Vương quốc Akkad trở thành một vương quốc giàu có và hùng mạnh.

Bên cạnh đó, Sargon Đại đế còn được nhớ đến là người đã thành lập một xã hội mà người yếu được bảo vệ. Truyền thuyêt kể rằng, trong triều đại của ông, không ai phải cầu xin thức ăn, những người góa phụ và trẻ mồ côi đều được bảo hộ. Nhưng một đặc điểm chính trong thời kỳ trị vì của ông cũng là những cuộc nổi loạn, như chính nhà vua từng nói kẻ thù của ông cũng phải đối mặt với một con sử tử con có răng và móng vuốt.

Sargon Đại đế được cho là mất vào khoảng năm $2279 \mathrm{TCN}$ và Rimush (con trai của Sargon) kế vị. Căn cứ vào danh sách vua Sumer thì Sargon Đại đế trị vì 56 năm, chết vì tuổi già.

Sau khi Vương quốc Akkad sụp đổ, khu vực Lưỡng Hà hình thành 2 cường quốc riêng biệt có chung hệ ngôn ngữ Akkad là Assyria ở phía Bắc và Babylon ở phía Nam. Sargon Đại đế cũng là chủ đề chính cho những câu chuyện huyền thoại trong văn học của người Assrrian và Babylona. Tát cả đều xoay quanh sự nghị lực vươn lên của Sargon Đại đế từ thân phận thấp hèn trở thành vị hoàng đế của đế chế đầu tiên của khu vực Lưỡng Hà.

Tài liệu tham khảo

Vũ Dương Ninh (Chủ biên), 1999, Lịch sử văn minh thế giới, Nxb Giáo dục, Hà Nội

Vương Quân Hoàng, 2007, Văn minh làm giàu \& nguồn gốc của cải, Nxb Chính trị Quốc gia, Hà Nội.

https://khoahocphattrien.vn/.../ky...

/2020060410355953p1c879.htm

https://www.ancient-origins.net/histor.../sargon-akkad-0010542

https://www.ancient.eu/Sargon_of_Akkad/

https://en.wikipedia.org/wiki/Sargon_of_Akkad

\#hoàngđế

\#lưỡnghà \#Sargon \#Akkad

Nguồn: Hoàng tộc phương đông 


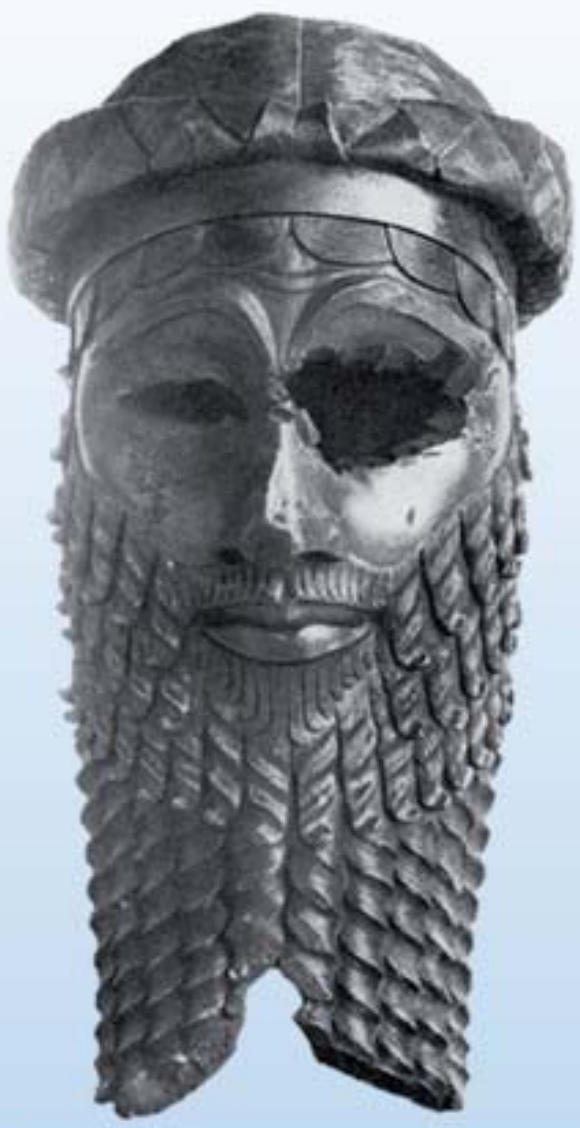

Đầu đồng của một vị vua của Akkad, nó được cho là đại diện của Sargon Đại đế, khai quật tại Nineveh (Iraq ngày nay, được trưng bày tại bảo tàng quốc gia Iraq).

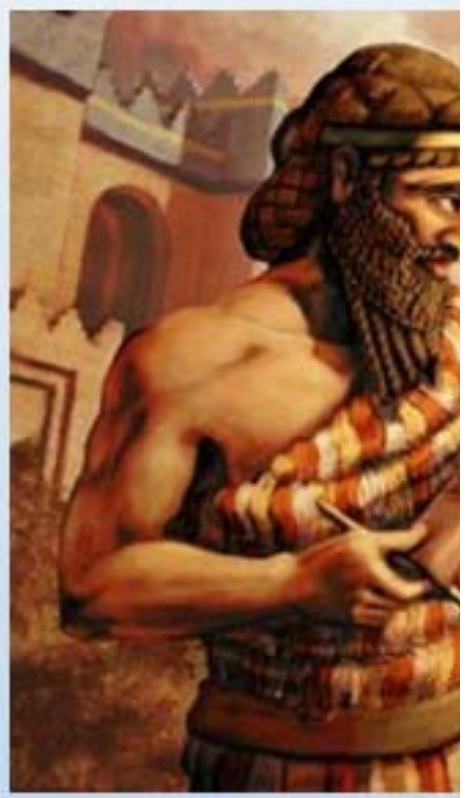

Sargon được la cho vua

\section{HOÀNG ĐẾ}

\section{Sargon của xứ Al}




\section{Tài liệu tham khảo}

[1] Vũ Dương Ninh. (1999). Lịch sử văn minh thế giới. Nxb Giáo dục, Hà Nội

[2] Vương Quân Hoàng. (2007). Văn minh làm giàu \& nguồn gốc của cải. Nxb Chính trị Quốc gia, Hà Nội.

[3] Quốc Hùng. (2019). Sargon xứ Akkad: Hoàng đế đầu tiên trong lịch sử. Khoa học \& Phát triển (ngày 2 tháng 7 ).

https://khoahocphattrien.vn/kham-pha/sargon-xu-akkad-hoangde-dau-tien-trong-lich-su/20190627023952764p1c879.htm

[4] Wu Mingren. (2019). Sargon of Akkad: Familiar and Legendary Tales of a Famous Mesopotamian King. (March 2). https://www.ancientorigins.net/history-famous-people/sargon-akkad-0010542

[5] Joshua J. Mark. (2009). Sargon of Akkad. Ancient History Encyclopedia (September 2).

https://www.ancient.eu/Sargon_of_Akkad/

[6] Wikipedia. (n.d.). Sargon of Akkad.

https://en.wikipedia.org/wiki/Sargon_of_Akkad 